\title{
İşitme Engellilere Yönelik Çevresel Ses Yönü Tespit Sistemi
}

\author{
Ahmet Reşit Kavsaoğlu ${ }^{1 *}$, Hasan $\mathrm{Camc1}^{2}$ \\ 1* Karabük Üniversitesi, Mühendislik Fakültesi, Biyomedikal Mühendisliği Bölümü, Karabük, Türkiye (ORCID: 0000-0002-4380-9075), kavsaoglu@karabuk.edu.tr \\ ${ }^{2}$ Karabük Üniversitesi, Mühendislik Fakültesi, Biyomedikal Mühendisliği Bölümü, Karabük, Türkiye (ORCID 0000-0002-7743-1277), hasancmci@ hotmail.com
}

(3rd International Congress on Human-Computer Interaction, Optimization and Robotic Applications June 11-13, 2021)

(DOI: $10.31590 /$ ejosat.952011)

ATIF/REFERENCE: Kavsaoğlu, A.R., \& Camcı, H., (2021). İşitme Engellilere Yönelik Çevresel Ses Yönü Tespit Sistemi. Avrupa Bilim ve Teknoloji Dergisi, (26), 203-207.

\begin{abstract}
$\ddot{O} \mathbf{z}$
İşitme engelli bireyler günlük hayatta birçok problemle karşı karşıya kalmaktadırlar. Bu problemlerin başında sesin nereden geldiğinin tespit etmekte güçlük çekilmesi gelmektedir. Bu çalı̧̧mada, işitme engelli bireylerin çevresel ses kaynaklarını algılamalarına yönelik bir ses yönü tespit sistemi önerilmektedir. Önerilen bu sistemde insan kafa yapısı model alınarak kafa mankeni kulaklarına yerleştirilen iki adet mikrofon kullanılmaktadır. Bu mikrofonlar aracılığıyla kaydedilen çevresel ses verileri USB ses kartları aracılığıyla LattePanda tek kart bilgisayara aktarılmaktadır. Aktarılan bu ses verileri filtreleme ve normalizasyon işlemlerinden geçirilerek on beş adet öznitelik oluşturulmaktadır. Bu öznitelikler çevresel sekiz farklı bölgeden alınan ses verileri için ayrı ayrı elde edilmektedir. Çevresel ses kaynağı bir BlueTooth hoparlör ile kafa mankeni etrafındaki sekiz farklı bölgeye ayrılmış platform ortamı kullanılarak oluşturulmaktadır. Bu çevresel ses kaynağı kullanılarak her bir bölge içerisinde üç farklı konum ve bu konumlarda dört farklı ses seviyesi olmak üzere her bir bölge için on iki farklı ses kaydı ile veri seti oluşturulmaktadır. Bu veri setini oluşturmak için $\mathrm{C \#}$ programlama dilinde bir arayüz tasarımı gerçekleştirilmiştir. $\mathrm{Bu}$ arayüz, sistem modeli iyileştirilmesi ve geliştirilmesine yönelik veri seti hazırlamak için farklı denemelerin yapılabilmesini sağlamaktadır. Hazırlanan bu veri seti ML.NET kütüphanesinde bulunan karar ağaçları, lineer destek vektör makinesi, olasılıksal dereceli azalma, tek katmanlı ve çok katmanlı Perceptron algoritmaları kullanılarak sistem modelleri oluşturulmaktadır. Bu modeller karşılaş̧ırıldığında performans değerlendirmesinde en başarılı sonuç tek katmanlı Perceptron algoritması ile oluşturulan sistem modeli olmuştur. Tek katmanlı Perceptron algoritması ile oluşturulan model $\% 87,5$ başarı oranıyla çevresel ses yönü tespit etmektedir. Elde edilen sonuçlar, işitme engellilere yönelik çevresel ses yönü tespit sisteminin gelecek için umut vaat ettiğini göstermektedir.
\end{abstract}

Anahtar Kelimeler: Ses yönü bulma, Sınıflandırma, Makine öğrenmesi, Perceptron algoritması, ML.NET.

\section{Surround Sound Direction Detection System For The Hearing Impaired}

\begin{abstract}
Hearing-impaired individuals face many problems in daily life. One of these problems is the difficulty in determining where the sound is coming from. In this study, a sound direction detection system is proposed for hearing impaired individuals to perceive surround sound sources. In this proposed system, two microphones are used, which are placed on the ears of the head manikin, taking the human head structure as a model. Surround sound data recorded by these microphones are transferred to a LattePanda single card computer via USB sound cards. Fifteen features are created by filtering and normalizing these transmitted sound data. These features are obtained separately for sound data from eight different surrounding regions. The surround sound source is created using a BlueTooth speaker and a platform environment divided into eight different regions around the head manikin. Using this surround sound source, a data set is created with twelve different sound recordings for each region, with three different locations in each region
\end{abstract}

* Sorumlu Yazar: Karabük Üniversitesi, Mühendislik Fakültesi, Biyomedikal Mühendisliği Bölümü, Karabük, Türkiye, ORCID: 0000-0002-4380-

9075, kavsaoglu@karabuk.edu.tr 
and four different sound levels at these locations. An interface has been designed in the $\mathrm{C}$ \# programming language to create this data set. This interface enables different trials to be made to prepare a data set for system model improvement and development. System models are created using decision trees, linear support vector machine, stochastic gradient descent, single-layer and multi-layer Perceptron algorithms in the ML.NET library. When these models are compared, the most successful result in performance evaluation has been the system model created with the single-layer Perceptron algorithm. The model created with the single-layer Perceptron algorithm determines the surrounding sound direction with a success rate of $87.5 \%$. The results obtained show that the surround sound direction detection system for the hearing impaired is promising for the future.

Keywords: Finding sound direction, Classification, Machine learning, Perceptron algorithm, ML.NET.

\section{Giriş}

Türkiye'de işitme engelli yaklaşık 3 milyon kişi vardır. Dünya da ise bu sayının 76 milyon olduğu düşünülmektedir. Ancak bu sayıya işitme güçlüğü çekenlerin sayısının eklenmesiyle 500 milyon insanın günlük hayatta işitme problemleri ile karşı karşıya kaldığı bununla beraber hem sosyal hem psikolojik olarak yaşam kalitesinin düşmesine neden olduğu tespit edilmiştir. İşitme engelli bireyler için seslerin nereden ve hangi kaynaktan geldiğinin bilinmesi buna bağlı olarak da hem gelebilecek olan tehlikelere karşı önlem alınması hem de bireyler arası iletişimin sağlanması işitme engelli bireyler için hayati öneme sahiptir (Xue \& Qin, 2011; Y1ld1z, 2018; Yoo \& Yook, 2008).

İşitme engelli bireyler günlük hayatta birçok problemle karşı karşıya kalmaktadır. İşitme engelli bireylerin bu problemlere karşı gerekli tepkiyi verememesinden dolayı birçok iletişim ve gündelik problemler ortaya çıkmaktadır. 68 işitme engelli ve 68 sağlıklı çocuk ile gerçekleştirilen bir çalışmada Kid-KINDL yaşam kalitesi ölçeğine göre işitme engelli çocukların yaklaşık olarak yaşam kalitesinin \%15 daha az olduğu görülmektedir (Ekim \& Ocakçı, 2012). Yapılan bu çalışma ile bahsedilen problemleri giderebilmek ve işitme engelli bireylerin hayat kalitesini yükseltebilmektir.

Sesin nereden geldiğinin bilinmesi sadece işitme engelli bireylerde değil savunma sanayiinde ateşli silahların tespitinde, deprem gibi afetlerden sonra enkaz altında kalan kişilerin tespitinde, kalabalık içerisinde konuşan kişi tespitinde de kullanılabilir (Galangque \& Guirnaldo, 2019; Okuyama ve diğerleri, 2002). Sesin yönünün belirlenmesindeki ana unsurların başında kulak ve kulağın anatomik yapısı gelmektedir. Canlıların aynı mesafeden gelen farklı yöndeki ses kaynaklarını görmeden yönünü tespit edebilmeleri bu anatomik yapıdan kaynaklanmaktadır (Helvac1, 2005; Yağanoğlu, 2018).

Bu çalışmada çevresel ses yönü tespitine yönelik Şekil 1'de blok şeması verilen sistem tasarımı gerçekleştirilmektedir. Tasarlanan bu sistem iki mikrofon aracılığıyla ses verilerinin elde edilmesi, elde edilen verilere ön işleme aşamasında filtreleme yapılması, filtrelenen verileri 8 saniye aralıklarla çerçevelere bölünmesi, özniteliklerin çıkarılması, veri seti oluşturma, sınıflandırma modeli oluşturma ve sesin geldiği yönün tespit edilmesi işlemlerinden oluşmaktadır.

$\mathrm{Bu}$ çalışmanın gerçek hayata uyarlanabilmesi için yapay ortamda kullanılan mikrofon yapısı ile insan kulak yapısı benzerliği ön plana çıkmaktadır. Mikrofon ses algılama işlevini yön tayini yapmaksızın gerçekleştirirken, insan kulağı ise anatomisi gereği (kulak kepçesi, kulak memesi, orta kulak yolu vb.) ses yönü tayinini sağ-sol, ön-arka ilişkisi içerisinde tespit edebilmektedir (Litovsky ve diğerleri, 2006). Bu çalışmada canlılarda doğal olarak bulunan bu işitme sisteminden esinlenilerek çevresel ses yönü tespit edebilen yapay bir sistem geliştirilmektedir.

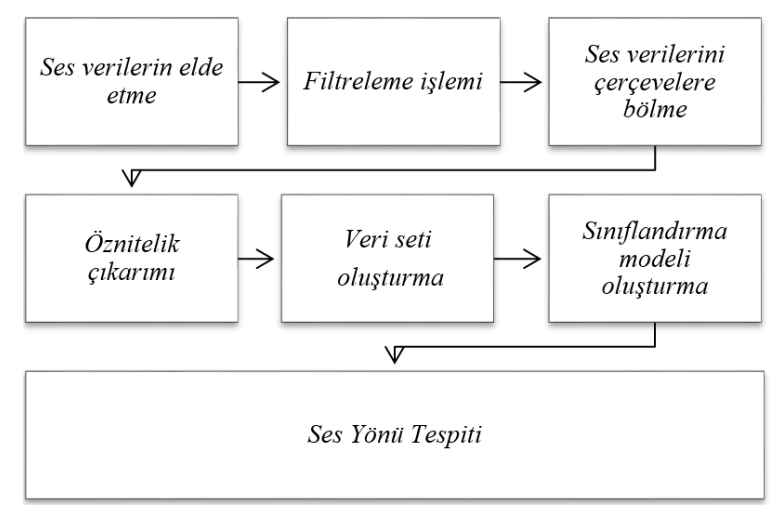

Şekil 1. Sistemin tasarımı blok şeması

\section{Materyal ve Metot}

Sesin yönünü tespit etmede büyük öneme sahip olan kulak kepçesi dış kulakta bulunmaktadır. Dış kulak, kulak kepçesi ile kulak kanalından oluşmaktadır. Kulak kepçesi kendine has şekli sayesinde sesin oluşturduğu hava basınç farklılığını toplamaktan ve gelen sesleri kulak içerisine aktarmaktan sorumludur. Sesin gelme yönünü ayırt etmemizi sağlayan bu yapı da kulak kepçesine gelen dalgalar kulak zarına ulaşmak için yaklaşık 2 $\mathrm{cm}$ uzunluğunda kulak kanalından geçerler. Bu iletim sırasında, kulak kanalı ve kulak kepçesinin yapısından dolayı, özellikle 3 $\mathrm{kHz}$ frekanslardaki ses dalgaları, şiddetleri artırılarak orta kulağa gönderilir. Ses dalgaları, kulak zarına çarparak titreşmesine neden olurlar ve iç kulakta bulunan salyangoz yapısı sayesinde beyne elektriksel ileti gönderilir ve bu sistem sayesinde işitme gerçekleştirilmektedir (Belgin, 2004; Litovsky ve diğerleri, 2006)

Sağlıklı bireylerde çevresel ses yönünün tespitinde kulak ile beyin arasındaki işitme sistemi bu çalışmada oluşturulan yapay sistemde mikrofon ve LattePanda tek kart bilgisayar kullanılarak sağlanmaktadır. Şekil 2'de tasarlanan sistemin prototip şemas1 deney platformu, kafa mankeni, mikrofonlar, USB ses kartları, çevresel ses kaynağı olarak bir BlueTooth hoparlör ve LattePanda tek kart bilgisayardan oluşmaktadır. Çevresel ses kaynağı kafa mankeni etrafında 1'den 8'e kadar numaralandırılmış bölgeler üzerinde gezdirilerek ses sinyali oluşturmaktadır. Mikrofonlar ve ses kartları aracılığıyla bu ses sinyalleri LattePanda tek kart bilgisayara aktarılmaktadır. LattePanda tek kart bilgisayarda yüklü bulunan C\# arayüz tasarımı ile ses sinyallerinden elde edilen öznitelikler gerçek zamanlı görüntülenmekte ve yapılan sınıflandırma sonuçlarına göre örneğin Şekil 2 'de ekran üzerinde birinci bölgede gösterilen yeşil dairenin 1'den 8'e kadar olan bir bölgede gösterimi gerçekleştirilmektedir. Sınıflandırma modeli oluşturmak için C\#'da bulunan ML.NET kütüphanesi kullanılmaktadır. 


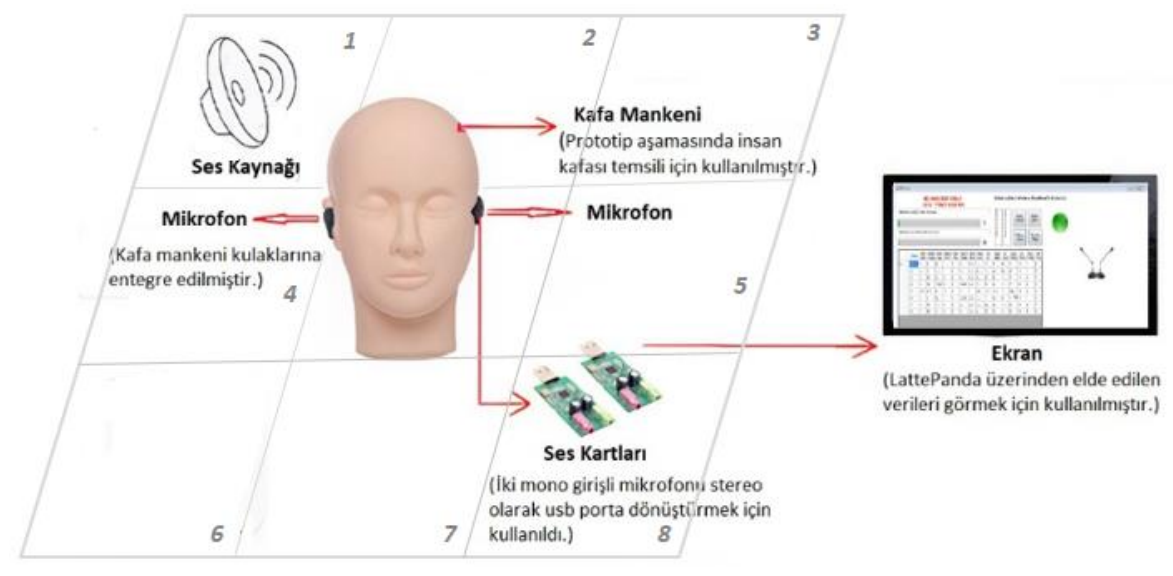

Şekil 2. Tasarlanan sistem prototip şeması

\subsection{Veri Seti}

Oluşturulan eğitim kümesi, kullanılacak modele uygun ve veri kümelerini ayırt edebilecek özelliklere sahip olmalıdır (Ho ve diğerleri, 2020). Mikrofonlar aracılığıyla elde edilen ham ses verileri filtreleme ve öznitelik çıkarımı aşamalarından geçirilerek makine öğrenmesi için elverişli veriler haline getirilmiştir. $\mathrm{Bu}$ çalışmada sol ve sağ mikrofon farklarının aritmetik ortalaması, standart sapması ve mutlak değerleri olmak üzere 3 öznitelik, sol ve sağ mikrofonlar için ayrı ayrı hesaplanan ortalama değer, standart sapma değeri, medyan ve mod değerleri olmak üzere 8 öznitelik, yine sol ve sağ mikrofonlar için ayrı ayrı ses verilerinin baştan ve sondan $\% 10$ 'luk kısmı hariç aralığından hesaplanan aritmetik ortalama değerleri, standart sapma değerleri olmak 4 öznitelik, toplamda 15 öznitelik oluşturulmaktadır.

Veri seti oluşturulurken Şekil 2'de gösterilen platform üzerindeki 1'den 8'e kadar bölgelere çevresel ses kaynağ 1 olarak taşınabilir BlueTooth hoparlör yerleştirilerek mikrofona gelen ses verileri 8'er saniyelik aralıklarla kaydedilmektedir. Literatürde bir çalışmada, veri kümesi analizi yapılacak sesin, olabildiğince farklı durum versiyonları içinde bulunmasından bahsetmektedir (Saltalı, 2015). Bu çalışmada da BlueTooth hoparlör her bölge içinde 3 ayrı konumda ve her konumda 4 farklı ses seviyesinde olacak şekilde ses verileri kaydedilerek toplamda tüm bölgeler dahil 96 farklı ses kayd1 gerçekleştirilmiştir. Böylelikle veri seti 15 öznitelik, 1 bölge etiketi ve 96 deneme olmak üzere 96x16 matristen oluşmaktadır. C\# programlama dili kullanılarak oluşturulan arayüzde elde edilen verileri tutabilmek ve görüntüleyebilmek için "DataGridView" kontrolü kullanılmaktadır. DataGridView kullanıcıya satır ve sütunlardan oluşan özelleştirilebilir tablo oluşturma imkanı sağlamaktadır. Bu çalışmada da verileri makine öğrenmesi için uygun olan Excel formatına aktarmadan önce görüntülenebilmesi için kullanılmıştır. Şekil 3 'te 8 bölge için 15 adet özniteliğin çıkarılmış "DataGridView" görüntüsü gösterilmektedir.

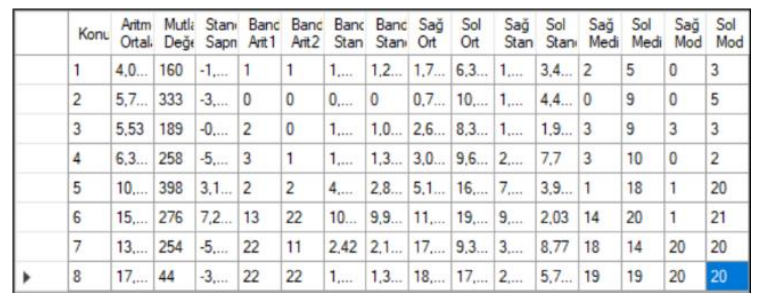

Şekil 3. Çalışmada kullanılan DataGridView kontrolünün görüntüsü
DataGridView'e aktarılan veriler C\# programlama dilindeki paketlerden "Microsoft.Office.Interop.Excel." paketi kullanılarak Excel'e aktarılmaktadır. Excel'e aktarılan veriler makine öğrenmesi için kullanılacak C\#'daki "ML.NET Model Builder" arayüzüne uygun olan ".csv, .tsv veya .txt" formatlarından ".csv" formatına kolaylıkla dönüştürülebilmektedir. Veri seti bahsedilen format ile makine öğrenmesinde model oluşturabilmeye hazır hale getirilmektedir.

\subsection{Arayüz}

Bu çalışmada daha önce bahsedilen 96 satır (denemeler) ve 16 adet sütun (öznitelikler ve etiket) dan oluşan veri seti C\# programlama dilinde oluşturulan arayüz ile elde edilmektedir. C\# programlama dilinde tasarlanan bu arayüz Şekil 4'de gösterilmektedir. Tasarlanan arayüz sayesinde ön işleme, öznitelik çıkarma ve veri seti oluşturma işlemleri gerçekleştirilebilmektedir. Arayüzdeki "Kaydı Başlat" butonu BlueTooth hoparlör herhangi bir bölgede konumlandırıldığında her deneme için 8'er saniyelik kaydı başlatmada kullanılmaktadır. Kayıt sonrası "Nitelik Çıkar" butonu ile elde edilen verilerden 15 adet öznitelik çıkartılmaktadır.

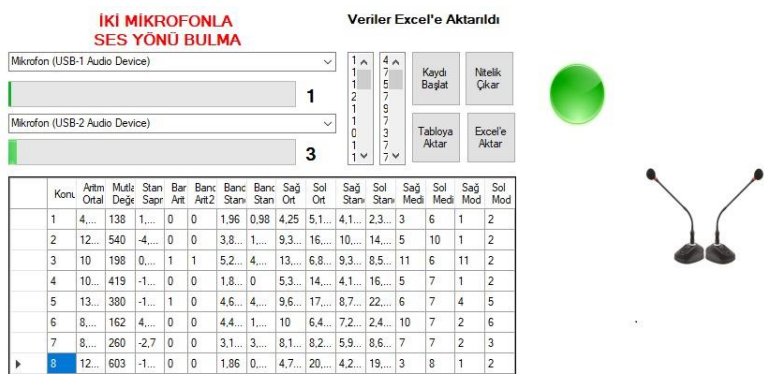

Şekil 4. Tasarlanan arayüz

Her denemede çıkartılan öznitelikleri veri setine eklemek için Arayüzdeki "Tabloya Aktar" buttonuna basılır. Tüm denemeler bittiğinde veri seti tamamlanmış olmakta ve makine öğrenmesinde model oluşturmak için Arayüzdeki "Excel'eAktar" butonuna basilarak veri set *.csv uzantılı olarak dışa aktarılmış olur. ML.NET Model Builder ile bu veri seti kullanılarak en uygun sistem modeli elde edilmektedir. Sonrasında bu model kullanılarak çevresel ses yön tespiti gerçekleştirilebilmekte ve Arayüzdeki yeşil daire mikrofon etrafındaki 8 bölgeden birinde gösterilmektedir. 


\subsection{Perceptron Modeli}

Sınıflandırma, makine öğrenmesinin popüler ve temel görevlerinden biridir (Harrington, 2012). Sinıflandırma, bilgisayara verilen öğrenme kümesi veri setine göre eğitilen modelin sonrasında yeni verileri sınıflandırmak için bu modelin kullanıldığı gözetimli öğrenme yaklaşımıdır. Sınıflandırmada eldeki veriler kullanılarak sistemin hem eğitilmesi hem de başarısının tarafsız bir şekilde ölçülmesi gerekir (Tan ve diğerleri, 2018). Bu başarı ölçümü ise "sınama kümesi" adı verilen öğrenme kümesinde yer almayan verilerin model kullanılarak incelenmesi ve doğru sınıflandırılmış örneklerin toplam sınama kümesi örneklerine oranı olarak ölçülür (Mallet ve diğerleri, 2000). Makine öğrenmesinde kullanılan modelin başarı yüzdesi ne kadar yüksekse modelin performansı da o kadar iyi kabul edilir. Makine öğrenmesi uygulamalarında birçok sınıflandırma algoritmaları yöntemi bulunmaktadır. $\mathrm{Bu}$ yöntemlerden bazıları şunlardır: Karar ağaçları, Naïve Bayes sınıflandırıcıları, lojistik regresyon, k-en yakın komşu algoritmaları, yapay sinir ağları vb. $\mathrm{Bu}$ yöntemlerden kullanılacak olan verilere en uygun olanı tercih edilmelidir. $\mathrm{Bu}$ çalışmada kullanılacak verilere en uygun ve en yüksek başarı oranı sağlayacak algoritma ML.NET Model Builder tarafindan belirlenmektedir.

Sınıflandırma işlemi model oluşturma, model değerlendirme ve modeli kullanma olarak üç aşamadan oluşur. Bu çalışmada bu aşamalar C\# programlama dilindeki ML.NET kütüphanesinin ML.NET Model Builder arayüzü kullanılarak gerçekleştirilmiştir. ML.NET Model Builder ile öğrenme veri kümesi için en başarılı algoritmanın "Perceptron" öğrenme algoritması olduğu sonucuna ulaşılmıştır. Kullanılan "Perceptron" algoritması en basit yapay sinir ağları modeli, yapay sinir ağları ise en çok tercih edilen makine öğrenmesi algoritmasıdır. Gözetimli bir öğrenme algoritması olan Perceptron algoritması yapay sinir ağları için önemli bir temel oluşturmaktadır (Holmes, 2013).

Perceptron modeli giriş ve çıkış değerleri katmanlarından oluşmaktadır. İleri beslemeli yapay sinir ağı modeli ve giriş katmanından çıkış katmanına doğru tek yönlü işlem gerçekleştiren bir yapıya sahiptir. Perceptron modelinde hata oranı ise çıktı verisi ile hedef veri arasındaki fark olarak kabul edilmektedir. Hata oranı, giriş değerlerine verilen ağırlık değerlerinin doğru değerler olmamasından kaynaklanmaktadır. Ağırlık değerlerinin hata oranı azaltılana kadar eğitilmesi ve buna göre yenilenmesi gerekmektedir. Perceptron algoritmasında eşik değeri en önemli kısımdır. Eşik değeri, sınıflandırmanın başarılı olduğunu belirleyen faktördür. Eşik değeri, giriş değerleri ile ağırlık değerlerinin çarpımı sonucunda çıkan değerin 1 veya 0 olarak döndürüleceğini belirlemektedir. Ĕger giriş değerleri ile ağırlık değerlerinin çarpımları toplamı eşik değerinden büyükse 1 , küçükse 0 değeri döndürülmektedir. Şekil 5'de $X 1, X 2$ ve $X 3$ ile gösterilen değerler giriş değerlerini; $W 1$, $W 2$ ve $W 3$ ile gösterilen değerler ise ağırlık değerlerini; t değeri en önemli faktör olan eşik değerini; Y değeri ise çıktı değerini gösterir. Eşitlik 1'de perceptron modelinin matematiksel gösterimi görülmektedir.

$$
Y=I\left(\sum_{i} w_{i} X_{i}-t\right) \text { veya } Y=\operatorname{sign}\left(\sum_{i} w_{i} X_{i}-t\right)
$$

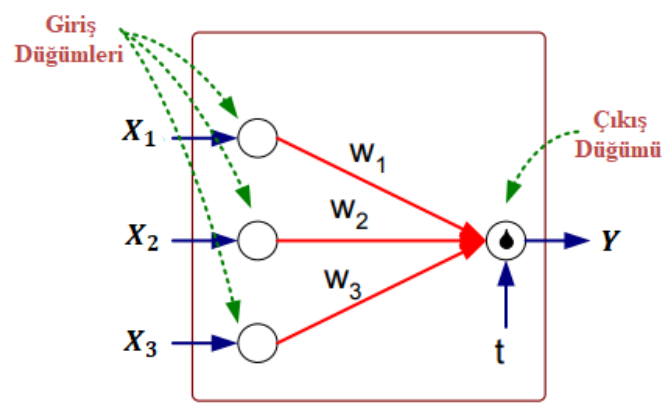

Şekil 5. Perceptron modeli (Tan ve diğerleri, 2018)

\section{Araştırma Sonuçları ve Tartışma}

Bu çalışmada oluşturulan sistem prototipinde kafa mankeni etrafindaki 8 farklı bölgeden BlueTooth hoparlör her bölge içinde 3 ayrı konumda ve her konumda 4 farklı ses seviyesinde olacak şekilde ses verileri kaydedilerek oluşturulan veri seti ML.NET Model Builder kullanılarak makine öğrenmesi modelleri oluşturulmuştur. Bu modellerden en yüksek başarı oranı sağlayan algoritmalardan beş tanesi sırasıyla tek katmanlı perceptron, doğrusal destek vektör makinesi, olasılıksal dereceli azaltma, çok katmanlı perceptron ve karar ağaçları algoritmaları olmuştur. Tablo 1 'de veri setine uygulanan algoritmalar ve başarı oranları gösterilmektedir.

Tablo 1. Veri Setine Uygulanan Algoritmalar ve Başarl Oranları

Denenen Algoritma

Başarı Yüzdesi \%

$\begin{array}{ll}\text { Tek Katmanlı Perceptron } & \% 87,5\end{array}$

Doğrusal Destek Vektör Makinesi $\quad \% 85,3$

Olasılıksal Dereceli Azalma

$\% 81,8$

Çok Katmanlı Perceptron

$\% 79,1$

Karar A ğaçları

$\% 77,8$

$\mathrm{Bu}$ çalışmada öğrenme kümesi kullanılarak oluşturulan ve \%87,5 başarı yüzdesine sahip model, öğrenme kümesinde yer almayan yeni veriler kullanılarak test edilmiştir. Modele "sınama kümesi” olarak da isimlendirilebilecek sınıf değerleri bilinen veriler girilmiş ve girilen veriler neticesinde döndürülen sınıf değerlerinin sınama kümesindeki sınıf değerleriyle aynı olduğu gözlemlenmiştir. ML.NET Model Builder kullanılarak oluşturulan makine öğrenmesi modeli, Şekil 6'da görüldüğü gibi girilen nitelik değerleri sonucunda $\% 83$ başarı yüzdesiyle "Konum" değeri 1 olarak adlandırılan bölgeyi, diğer bir deyişle çevresel sesin geldiği bölgeyi tespit edebilmektedir. $\mathrm{Bu}$ çalışmanın tüm bölgeler için genel başarı yüzdesi $\% 87,5$ olmaktadir. 


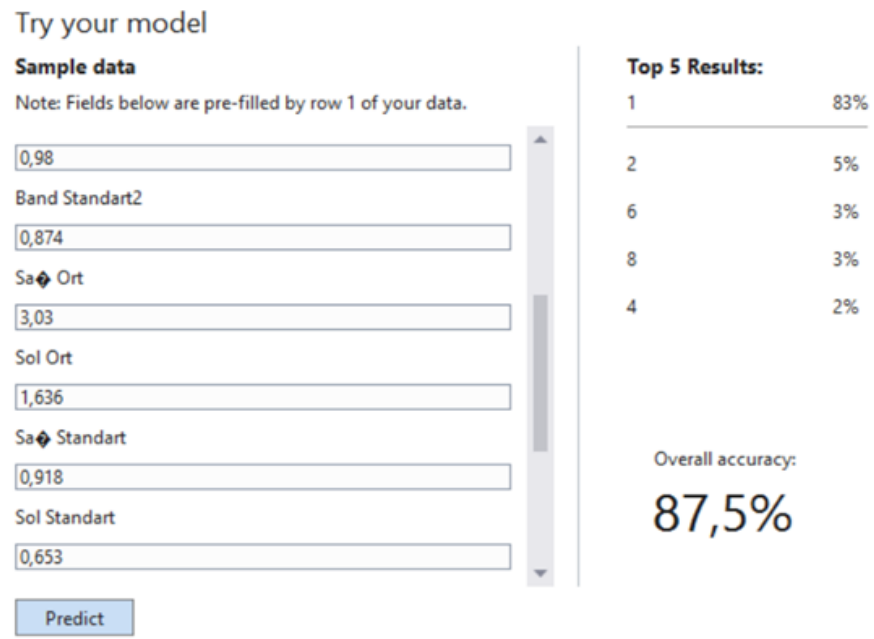

Şekil 6. ML.NET Model Builder model deneme sayfası

\section{Sonuç}

$\mathrm{Bu}$ çalışmada, işitme engelli bireylerin çevresel ses kaynaklarını algılamalarına yönelik bir ses yönü tespit sistemi gerçekleştirilmiştir. Önerilen bu sistem kafa mankeni kulaklarına yerleştirilen iki adet mikrofon, çevresel ses kaynağı olarak BlueTooth hoparlör, kafa mankeni etrafında sekiz farklı bölgeye ayrılmış platform, USB ses kartları ve LattePanda tek kart bilgisayar kullanılarak tasarlanmıştır. Veri seti oluşturmak için C\# programlama dilinde bir arayüz tasarımı gerçekleştirilmiştir. $\mathrm{Bu}$ arayüz ile elde edilen veri seti ML.NET kütüphanesinde bulunan karar ağaçları, lineer destek vektör makinesi, olasılıksal dereceli azalma, tek katmanlı ve çok katmanlı Perceptron algoritmaları kullanılarak sistem modelleri oluşturulmuştur. Oluşturulan bu modeller karşılaştırıldığında performans değerlendirmesinde en başarılı sonuç tek katmanlı Perceptron algoritması ile oluşturulan sistem modeli olmuştur. Tek katmanlı Perceptron algoritması ile oluşturulan bu sistem modeli ile $\% 87,5$ başarı oranıyla çevresel ses yönü tespit edilmektedir.

\section{Kaynakça}

Belgin, E. (2004). Çalışma yaşamında gürültü ve işitmenin korunmasl: Işsitme Fizyolojisi. Türk Tabipler Birliği Yayınlar1.

Ekim, A., \& Ocakçı, A. (2012). 8-12 yaş arası işitme engelli çocuklarda yaşam kalitesi. Ankara Sağllk Hizmetleri Dergisi, 11(1), 17-23.

Galangque, C. M. J., \& Guirnaldo, S. A. (2019). Gunshot classification and localization system using artificial neural network (ANN). Proceedings of 2019 International Conference on Information and Communication Technology and Systems, ICTS 2019, 98-102. https://doi.org/10.1109/ICTS.2019.8850937

Harrington, P. (2012). Machine Learning in Action. Manning Publications Co.

Helvacı, A. (2005). Anatomik Yapıların Sesin Harmonik Yapısı ve Tını Değişiklikleri Üzerindeki Etkileri. Uludă̆ Üniversitesi Ĕ̆itim Fakültesi Dergisi, 18(1), 123-134.

Ho, S. Y., Phua, K., Wong, L., \& Bin Goh, W. W. (2020). Extensions of the External Validation for Checking Learned Model Interpretability and Generalizability. Patterns, 1(8). https://doi.org/10.1016/j.patter.2020.100129

Holmes, J. H. (2013). Knowledge Discovery in Biomedical Data: Theory and Methods. Methods in Biomedical
Informatics: A Pragmatic Approach, 179-240. Elsevier. https://doi.org/10.1016/B978-0-12-401678-1.00007-5

Litovsky, R. Y., Johnstone, P. M., \& Godar, S. P. (2006). Benefits of bilateral cochlear implants and/or hearing aids in children. International Journal of Audiology, 45(1), 78-91. https://doi.org/10.1080/14992020600782956

Mallet, Y., Coomans, D., \& de Vel, O. (2000). Application of adaptive wavelets in classification and regression. Data Handling in Science and Technology, 22(1), 437-456. Elsevier. https://doi.org/10.1016/S0922-3487(00)80043-X

Okuyama, F., Takayama, J.-Y., Ohyama, S., \& Kobayashi, A. (2002). A study on determination of a sound wave propagation direction for tracing a sound source. Proceedings of the 41st SICE Annual Conference. SICE 2002., 1102-1104.

Saltalı, İ. İ. (2015). Sahne Analizi için Ses Kaynă̆ İstanbul Teknik Üniversitesi, Fen Bilimleri Enstitüsü, Yüksek Lisans Tezi.

Tan, P., Steinbach, M., Karpatne, A., \& Kumar, V. (2018). Introduction to data mining (2nd Edition). Artificial Neural Networks

Xue, H., \& Qin, S. (2011). Mobile motion gesture design for deaf people. The 17th International Conference on Automation and Computing, 46-50.

Yağanoğlu, M. (2018). Duyma Engelliler için Giyilebilir Titreşim Tabanlı Ses Tanıma Uygulamaları. Karadeniz Teknik Üniversitesi, Fen Bilimleri Enstitüsü, Doktora Tezi.

Yıldız, D. Z. (2018). İşitme engelli turizmi (sessiz turizm): Dünya ve Türkiye. Süleyman Demirel Üniversitesi Vizyoner Dergisi, 103-117. https://doi.org/10.21076/vizyoner.339776

Yoo, I. C., \& Yook, D. (2008). Automatic sound recognition for the hearing impaired. IEEE Transactions on Consumer Electronics, 54(4), 2029-2036. 